\title{
Association between apathy and regional cerebral blood flow in patients with idiopathic normal pressure hydrocephalus
}

\author{
Hideki Kanemoto*, Hiroaki Kazui, Takashi Suehiro, Shingo Azuma, Syunsuke Sato, Yukiko Suzuki, Kenji Yoshiyama \\ From Hydrocephalus 2015 \\ Banff, Canada. 18-21 September 2015
}

\section{Introduction}

Apathy is a common symptom in idiopathic normal pressure hydrocephalus (iNPH). However, the neuroanatomical bases of apathy in iNPH has not been well examined. We assessed the relationship between improvement of apathy and change of regional cerebral blood flow (rCBF) after shunt surgery.

\section{Methods}

We recruited $20 \mathrm{iNPH}$ patients who had apathy before shunt surgery. They were tested about apathy with Neuropsychiatric Inventory (NPI) and cognitive function with Mini-mental State Examination (MMSE) and Frontal Assessment Battery (FAB). They were also evaluated quantitative rCBFs of 32 regions-of-interests (ROIs) with 123IIMP single photon emission computed tomography (SPECT) using the autoradiography method. All the evaluations were conducted both before and 3 months after shunt surgery. They were classified into two subgroups; one was improved apathy (APA+) and another was not (APA-). The changes of rCBFs after the shunt were evaluated in each subgroup, respectively. In addition, we assessed the correlations between the changes of apathy and cognitive functions after shunt surgery.

\section{Results}

Ten patients categorized in APA+ group. In APA+ group, rCBFs in 3 ROIs, bilateral anterior cingulate cortices (ACC) and right caudate nucleus, were significantly improved after shunt surgery. In APA-group, rCBFs in 2 ROIs, splenium of corpus callosum and right amygdala, were significantly improved after shunt surgery. A significant correlation was

\footnotetext{
* Correspondence: hkanemoto0427@gmail.com

Department of Psychiatry Osaka University Graduate School of Medicine,
} Japan

Submit your next manuscript to BioMed Central and take full advantage of:

- Convenient online submission

- Thorough peer review

- No space constraints or color figure charges

- Immediate publication on acceptance

- Inclusion in PubMed, CAS, Scopus and Google Scholar

- Research which is freely available for redistribution 